\title{
Supraorbital Keyhole Approach for Intracranial Aneurysms : Transitioning from Concerns to Confidence
}

\author{
Jaechan Park \\ Department of Neurosurgery and Biomedical Research Institute, School of Medicine, Kyungpook National University, Daegu, Korea
}

For surgical minimalism to reduce iatrogenic traumatization, a supraorbital keyhole approach has already been successfully applied to treat many unruptured anterior circulation aneurysms. However, using this minimal approach also raises several technical concerns due to the small cranial opening and cosmetic impact of a facial incision. Yet, such technical limitations can be overcome by using favorable surgical indications, slender surgical instruments, and optimized surgical techniques, while excellent cosmetic outcomes can be achieved using a short skin incision located $<1 \mathrm{~cm}$ from the supraorbital margin, reconstruction of any bone defects around the bone flap, and meticulous wound closure. Thus, given such reassuring surgical results, in terms of the clipping status, neurological effects, and cosmetic outcomes, any concerns can be transitioned into confidence.

Key Words : Craniotomy · Intracranial aneurysm · Minimally invasive surgical procedures.

\section{INTRODUCTION}

Neurosurgical minimalism to reduce iatrogenic traumatization involves a variety of techniques intended to minimize the surgical wound, pain, complications, and hospital stay, along with avoiding neurological deficits ${ }^{11,13,20,21,29)}$. Since the introduction of a concept of keyhole approach by Perneczky and colleagues $^{33)}$, a supraorbital keyhole approach is commonly applied for treating anterior circulation aneurysms and tumorous lesions in the parasellar and suprasellar regions $s^{7,8,10,22,28,35)}$. As most aneurysms are located at or around the circle of Willis, a supraorbital keyhole approach using a supra-eyebrow skin incision facilitates straightforward access to the lesions, allowing visualization of deep-seated lesions and achievement of the surgical goals $s^{7,8,10,12,13,22,26)}$.

However, a supraorbital keyhole approach still presents certain technical and cosmetic challenges. Therefore, this report attempts to assuage such concerns by suggesting solutions based on the author's surgical experience of more than 600 cases using a supraorbital keyhole approach for unruptured aneurysms.

\section{SURGICAL TECHNIQUE FOR INTRACRANIAL ANEURYSMS}

\section{Supraorbital minicraniotomy}

The patient is placed in a supine position with the head ro-

- Received : February 8, 2019 • Revised : March 27, $2019 \bullet$ Accepted : April 4, 2019

- Address for reprints : Jaechan Park

Department of Neurosurgery, Kyungpook National University Hospital, 130 Dongdeok-ro, Jung-gu, Daegu 41944, Korea

Tel : +82-53-200-5647, Fax : +82-53-423-0504, E-mail : jparkmd@hotmail.com, ORCID : https://orcid.org/0000-0001-7572-3260

This is an Open Access article distributed under the terms of the Creative Commons Attribution Non-Commercial License (http://creativecommons.org/licenses/by-nc/4.0) which permits unrestricted non-commercial use, distribution, and reproduction in any medium, provided the original work is properly cited. 
tated contralaterally 20 degrees and slightly extended. No head fixation is used, as preferred by the author. In addition, no central venous line placement, mannitol infusion, or lumbar drainage of the cerebrospinal fluid (CSF) is applied when clipping clipping small unruptured aneurysms.

The supra-eyebrow skin incision runs laterally from the midpupillary line, measuring $3.5 \mathrm{~cm}$ in length. To avoid injury to the supraorbital nerve transmitting through the supraorbital foramen, the skin incision is not extended medially from the midpupillary line. The skin incision is located at or within $1 \mathrm{~cm}$ of the supraorbital margin to avoid the frontal branch of the facial nerve, and positioned just above the eyebrow in most women and in the upper part of the eyebrow in some men.

The underlying muscles, including the frontalis, corrugator supercilii, and temporalis muscle, are then cut using a monopolar cautery. While the temporalis muscle is elevated using a monopolar cautery, wide subcutaneous undermining outside the temporalis muscle is performed using a blunt dissector to avoid thermal damage to the frontal branch of the facial nerve. When medial undermining toward the supraorbital foramen, caution is needed to avoid any supraorbital nerve injury.

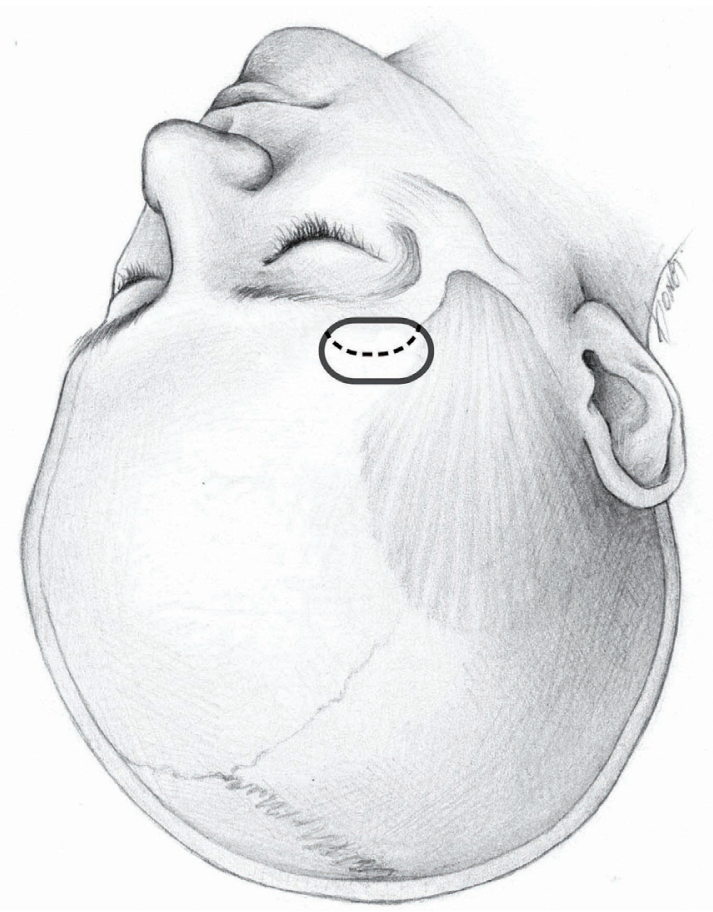

Fig. 1. Cranial opening for ICA and $A C O A$ aneurysms. Dotted line is dural incision. ICA : internal carotid artery, $\mathrm{ACOA}$ : anterior communicating artery.
A frontobasal lateral burrhole is drilled first. When using a high-speed drill with a footplate attachment to create a craniotomy, wide subcutaneous undermining allows extensive unidirectional skin retraction in front of the drill advancement using a retractor held by an assistant. As a result, tis facilitates a craniotomy that is larger than the opening made by the skin incision ${ }^{15,20,22,27)}$. A supraorbital bone flap with a diameter of $\leq 2$ $\mathrm{cm}$ is commonly created and sufficient for small anterior circulation aneurysms. In cases of complex or large aneurysms or an unexperienced surgeon, a slightly longer skin incision and larger craniotomy are recommended.

While a supraorbital mini-craniotomy yields a very small cranial opening, the size and extent of the opening are inevitably affected by the location and size of the aneurysm. Internal carotid artery (ICA) aneurysms require the smallest cranial opening, extending from the frontobasal lateral burrhole toward the midpupillary line (Fig. 1). Meanwhile, middle cerebral artery (MCA) aneurysms require a slight lateral extension of the cranial opening by drilling the sphenoid ridge to facilitate dissection of the sylvian fissure (Fig. 2). In cases of lowpositioned posterior communicating artery (PCoA) aneurysms, a supraorbital mini-craniotomy with a height $\geq 2 \mathrm{~cm}$

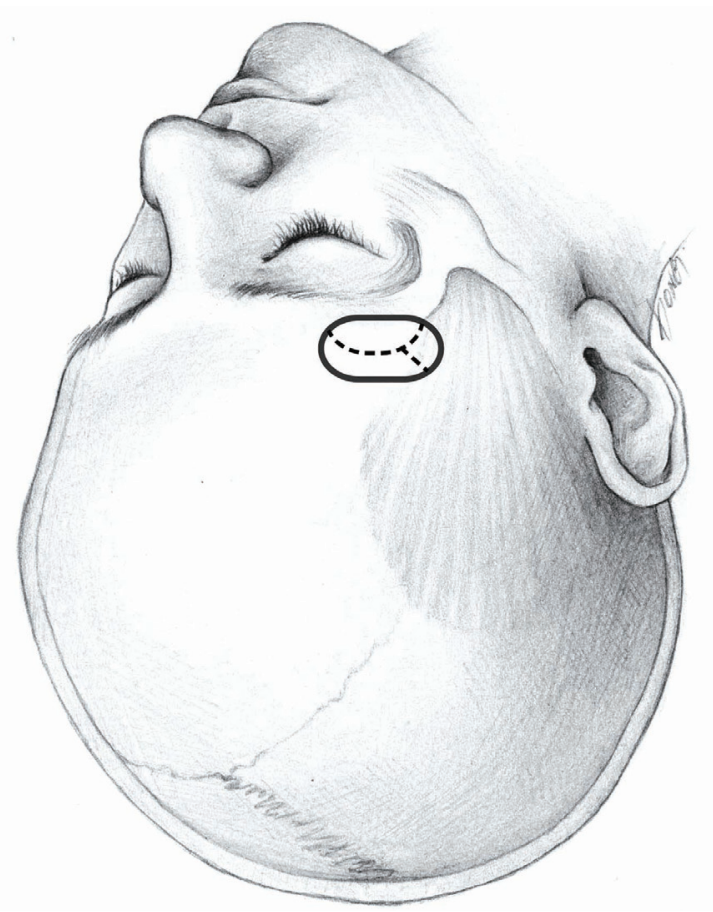

Fig. 2. Cranial opening for MCA aneurysms. Dotted line is dural incision. MCA : middle cerebral artery. 
may be required to introduce and direct a drill bit to the anterior clinoid process.

Six retraction sutures are placed at the edge of the skin incision instead of a self-retaining retractor. The inner edge of the craniotomy above the orbital rim is then drilled and beveled. In cases of ICA aneurysms and anterior communicating artery $(\mathrm{ACoA})$ aneurysms, the frontal floor prominences are drilled and flattened for subfrontal access, whereas in cases of MCA aneurysms, the supra-orbital craniotomy is marginally extended laterally and the sphenoid ridge slightly drilled toward the sylvian fissure.

The dura is opened in a semicircular fashion with the base at the orbital rim. A dural incision extending slightly beyond the cranial opening allows a more spacious surgical corridor toward the basal cisterns. For MCA aneurysms, an additional dural incision, as in Fig. 2, facilitates surgical access to the sylvian fissure.

The intradural procedures according to the location of the aneurysm are explained in the following sections. Thereafter, the dural incision is sutured. Epidural application of hemostatic patches along the dural suture line and bone margin in addition to intradural infusion of saline eliminate the necessity of dural tenting sutures. If needed, dural tenting sutures can also be placed along the bone edge using an anchor screw technique ${ }^{14)}$. The bone flap is then fixed in place using titanium plates and screws with a low profile. Finally, the burrhole and bone gaps around the bone flap need to be reconstructed, as even a small bone defect under the skin of the forehead can be noticeable and disfiguring. For this, biocompatible materials are recommended, such as a porous high-density polyethylene implant and hydroxyapatite cement ${ }^{6)}$.

\section{ICA aneurysms}

Following a curved dural incision, a narrow brain spatula is carefully slid over the base of the frontal lobe toward the carotid and optic nerve cisterns with the use of an operating microscope. The basal cisterns are then opened to drain the CSF, for brain relaxation, and to achieve sufficient working space. An intraoperative mannitol infusion is not required in the case of unruptured aneurysms.

For supraclinoid ICA aneurysms, including aneurysms arising at the PCoA origin or anterior choroidal artery (AChA) origin, medial dissection of the sylvian fissure allows sufficient frontal lobe retraction without temporal lobe traction and vi- sualization up to the carotid bifurcation. A supraorbital keyhole approach provides exactly the same surgical perspective as a pterional approach for supraclinoid ICA aneurysms ${ }^{20,30)}$. The ICA is located in the center of the surgical field.

For PCoA aneurysms, dissection of the carotid cistern is performed by lateral rolling of the arachnoid adherent to the ICA to expose the aneurysm base and origins of the PCoA and AChA. A temporary clip is then applied to the ICA proximal to the PCoA origin, while a permanent clip is applied to the aneurysm neck between the PCoA and AChA, after defining the proximal and distal aspects of the aneurysm neck ${ }^{20,30)}$.

For AChA aneurysms, the critical issue is determining the exact location of the AChA origin and the trajectory of the artery. This is achieved via rigorous visual scrutiny under high microscopic magnification. Here, a straight clip is preferred and applied across the aneurysm neck perpendicular to the axis of the ICA. A clip blade proximal to the aneurysm is then positioned away from the AChA origin, while the distal blade is positioned close to the ICA wall9). The AChA patency and safety are ascertained using indocyanine green angiography and neurophysiological monitoring using a motor-evoked potential. Smaller supraorbital craniotomies are adequate for ICA aneurysms rather than ACoA aneurysms or MCA aneurysms.

\section{MCA aneurysms}

The supraorbital craniotomy is extended a few millimeters laterally for MCA aneurysms. The surgical microscope is directed laterally toward the sylvian fissure and a narrow brain spatula is slid over the lateral aspect of the frontal lobe toward the sylvan fissure ${ }^{5,11)}$. Slight retraction of the lateral frontal lobe hen exposes the sylvian fissure and allows the opening of the fissure. Thereafter, slow drainage of the CSF through the opening of the sylvian fissure facilitates the dissection of the sylvian fissure.

For MCA bifurcation aneurysms at the MCA genu, the sylvian fissure at the pars triangularis is dissected focally up to 2 $\mathrm{cm}$ to achieve straightforward access to the aneurysm. This inevitably involves cutting a few small fronto-sylvian veins depending on their location. Meanwhile, for M1 aneurysms proximal to the MCA genu at the origin of an early frontal artery or early temporal artery, a more proximal segment of the sylvian fissure is dissected. 


\section{ACoA aneurysms}

A supraorbital keyhole approach can be applied for inferioror anterior-directing low-positioned ACoA aneurysms without considerable difficulty ${ }^{22,34)}$. However, a pterional-transsylvian approach or anterior interhemispheric approach is favored for superior-directing or high-positioned ACoA aneurysms to reduce the brain retraction.

As the brain retractor is placed in a lateral direction to an ACoA aneurysm in a pterional-transsylvian approach, this means the posterior part of the olfactory tract is retracted. In contrast, for a supraorbital keyhole approach, the retractor is placed subfrontally in an anterior direction via a supraorbital mini-craniotomy and the anterior part of the olfactory tract is retracted (Fig. 3). Retraction of the anterior part of the olfactory tract is considered more likely to produce avulsion of the olfactory nerve from the cribriform plate ${ }^{2,311}$. Thus, while the basic surgical procedures are similar, the direction of the brain retraction and surgical perspective are actually different between a supraorbital keyhole approach and pterional approach. Once the carotid cistern, proximal sylvian fissure, chiasmatic cistern, and interhemispheric fissure are all dissected, the A1 segment is then followed to the ACoA complex.

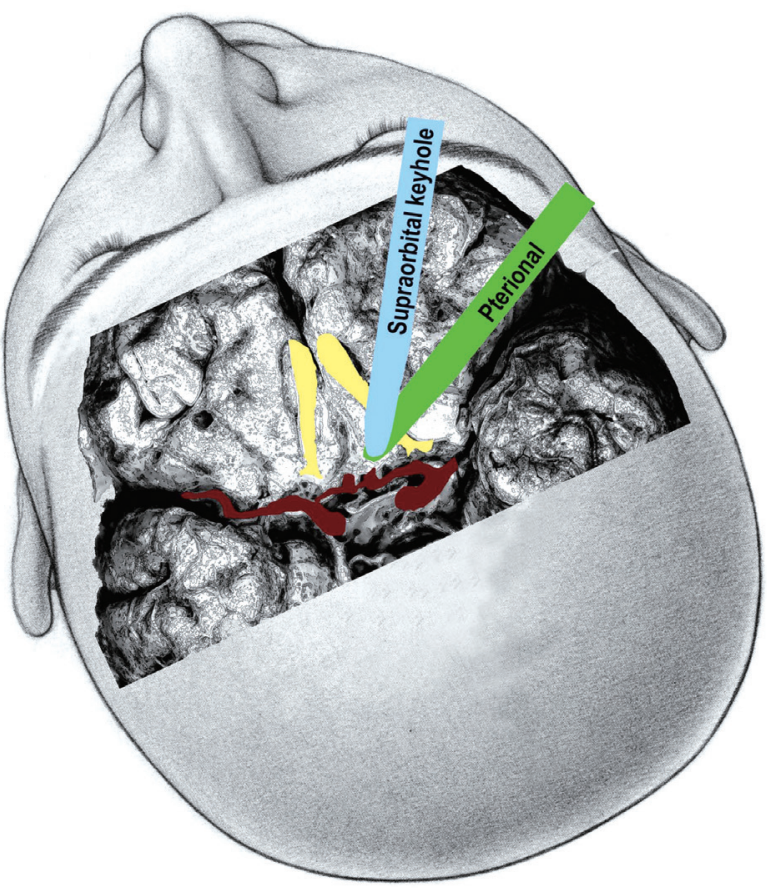

Fig. 3. Location of the brain spatula applied to the inferior surface of the frontal lobes in a supraorbital keyhole approach and pterional approach for ACoA aneurysms. ACoA : anterior communicating artery.
If needed, the gyrus rectus is also resected.

\section{TECHNICAL CONCERNS AND SOLUTIONS}

Since a supraorbital mini-craniotomy with a supra-eyebrow incision creates a very small cranial opening with a diameter $\leq 2 \mathrm{~cm}$, this imposes many technical limitations and shortcomings. First, the viewing angles are narrow and the intraoperative light is reduced, although the latter is no longer a problem with recent surgical microscopes delivering more light

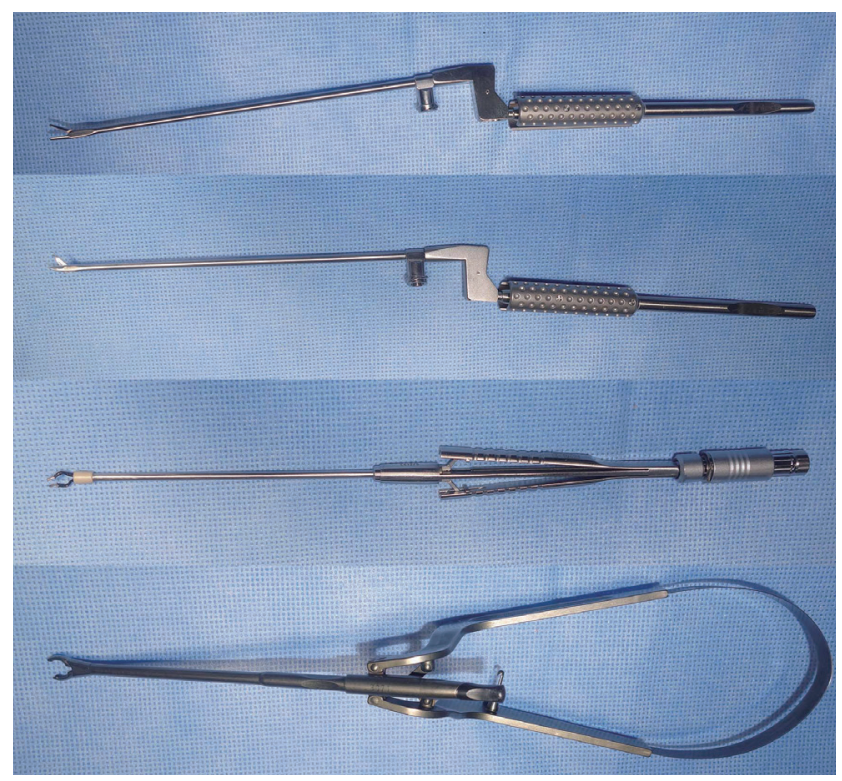

Fig. 4. Single-shaft slender-type surgical instruments, including microforceps, microscissors, bipolar coagulator, and aneurysm clip applier.

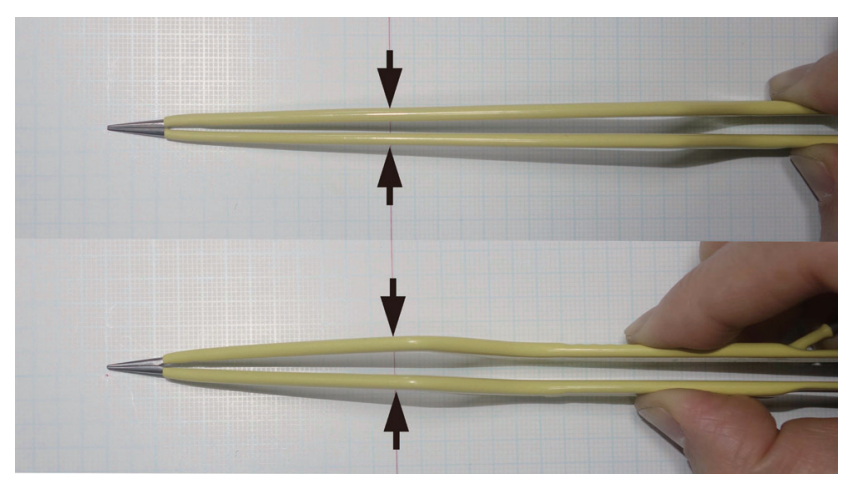

Fig. 5. Long and short bipolar coagulation forceps. The long bipolar coagulation forceps have a narrower configuration in the anterior part. Arrows indicate the width of the bipolar coagulation forceps at the level of the craniotomy opening. 
with higher-contrast images in narrow and deep canals. However, if hidden regions are problematic for microscopic visualization, an angled endoscope or surgical micro-mirror can be used to look around corners or behind structures.

Second, the small cranial opening reduces the maneuverability of the surgical instruments, yet this can also be overcome with the use of appropriate surgical instruments. While conventional aneurysm clip appliers, microscissors, and bipolar coagulation forceps have limited maneuverability in a narrow corridor, new single-shaft slender-type instruments are now commercially available that can operate freely in such narrow space (Fig. 4). In addition, in cases of using the conventional types of instruments, longer instruments provide more free maneuverability. For example, longer bipolar coagulation forceps have a narrower configuration in the anterior parts when closed (Fig. 5). Furthermore, due to the limited maneuverability of surgical instruments in keyhole surgery, the aneurysm needs to be accessed via the most direct and straightforward route without unnecessary intraoperative navigation. Thus, careful and clean arachnoid dissection is required to minimize venous bleeding, avoid a dim operative field, and facilitate surgical processes. Meanwhile, the margin of the small cranial opening can be used to support the surgical instruments to reduce any tremor for the surgeon, which is actually a critical advantage of keyhole surgery.

Third, the small cranial opening provides a uniportal microsurgical procedure with essentially coaxial control of the surgical instruments. Technical limitations due to coaxial instrument maneuverability are normally not problematic for most small saccular aneurysms, due to the use of aneurysm clips with various configurations, along with gentle mobiliza- tion of the parent artery and aneurysm using a suction tip in the left hand. However, such limitations can be problematic in certain complicated cases, which require the development of new surgical techniques ${ }^{17,18)}$. For example, tying a knot in a microsuturing procedure is very difficult in a deep narrow surgical field. While an easy procedure when the two instruments are positioned with a wide angle in a shallow and wide surgical field, it becomes very difficult when using coaxial control of the two surgical instruments in a deep and narrow surgical corridor. Therefore, a clip-knotting technique, which uses an aneurysm clip to hold both remaining ends of a thread that is sutured in a running manner, can replace the conventional knotting procedure in a deep and narrow surgical corridor $^{16)}$.

Fourth, a keyhole approach is essentially unidirectional, whereas a pterional approach can provide multidirectional access to the lesion. In cases of complex ACoA aneurysms, a pterional craniotomy provides both anterior and lateral access to the lesion and facilitates multidirectional dissection of the aneurysm and multidirectional application of the aneurysm clips.

\section{Surgical indications}

Determining the appropriate surgical indications is critical when applying a supraorbital keyhole approach due to its technical limitations. Small unruptured aneurysms arising at or around the level of the circle of Willis are particularly favorable for a supraorbital keyhole approach. Aneurysms arising from the supraclinoid ICA at the level of the PCoA origin or AChA origin, ICA bifurcation, A1 segment of an anterior cerebral artery, ACoA, M1 segment of an MCA, and MCA bi-

Table 1. Indications of a supraorbital keyhole approach for anterior circulation aneurysms according to the aneurysm location

\begin{tabular}{|c|c|c|}
\hline Aneurysm location & Favorable indications & Unfavorable or less favorable indications \\
\hline ICA & $\begin{array}{l}\text { - PCoA aneurysm } \\
\text { - AChA aneurysm } \\
\text {-ICA bifurcation aneurysm } \\
\text {-ICA superior wall aneurysm }\end{array}$ & $\begin{array}{l}\text { - ICA posterior wall aneurysm } \\
\text { - Low-lying supraclinoid ICA aneurysm } \\
\text { - Paraclinoid ICA aneurysm }\end{array}$ \\
\hline ACA & $\begin{array}{l}\text { - A1 segment aneurysm } \\
\text { - Inferior- or anterior-directing ACoA aneurysm } \\
\text { - Low-positioned ACoA aneurysm }\end{array}$ & $\begin{array}{l}\text { - Superior-directing ACoA aneurysm } \\
\text { - High-positioned ACOA } \\
\text { - Pericallosal artery aneurysm }\end{array}$ \\
\hline MCA & $\begin{array}{l}\text {-M1 segment aneurysm } \\
\text { - MCA bifurcation aneurysm }\end{array}$ & - Aneurysm distal to MCA genu \\
\hline
\end{tabular}

ICA : internal carotid artery, PCoA : posterior communicating artery, AChA : anterior choroidal artery, ACA : anterior cerebral artery, ACoA : anterior communicating artery, MCA : middle cerebral artery 
furcation can all be included ${ }^{15,22)}$. Table 1 summarizes the favorable indications for a supraorbital keyhole approach, along with the unfavorable and less favorable indications that require technical precautions.

The intraoperative visualization of a supraorbital keyhole approach to the ICA is nearly identical to that of a pterional approach. Aneurysms arising at the posterolateral wall of the ICA (PCoA and AChA aneurysms), superior wall of the ICA, and ICA bifurcation are all easy to access using a supraorbital keyhole approach. In particular, an unruptured PCoA aneurysm inducing oculomotor nerve palsy is a favorable indication for a supraorbital keyhole approach ${ }^{20)}$. Straightforward surgical access via a supraorbital keyhole approach, aneurysm neck clipping, and puncturing the aneurysm to relieve the oculomotor nerve of aneurysmal compression all serve to maximize the symptomatic resolution and minimize the surgical invasiveness.

However, certain ICA aneurysms are not favorable for a supraorbital keyhole approach. When the aneurysm arises at the posterior wall of the ICA, this may necessitate placement of an angled fenestrated clip encircling the ICA. For angular displacement of a fenestrated clip in a cranio-caudal or mediolateral direction, the clip applier should be moved a considerable amount, which is limited in the case of a keyhole surgery.

In addition, low-lying supraclinoid or paraclinoid ICA aneurysms that involve drilling of the anterior clinoid process also require a larger cranial opening than a supraorbital minicraniotomy with a small diameter of $\leq 2 \mathrm{~cm}$. In such cases, the following surgical approaches can be adequate : 1) a longer supra-eyebrow skin incision and resultant larger supraorbital craniotomy with a height $>2 \mathrm{~cm}, 2$ ) supraorbital mini-craniotomy combined with an orbital osteotomy, or 3) mini-pterional craniotomy with or without an orbital osteotomy.

Most MCA aneurysms arising at the M1 segment and MCA bifurcation can be clipped using a supraorbital keyhole approach. However, if the lesions are located beyond the MCA genu, a larger cranial opening is needed to expose them.

For ACoA aneurysms, a supraorbital keyhole approach only allows subfrontal access and the ipsilateral olfactory nerve is more compressed by the brain retractor than in the case of a pterional approach. Thus, while inferior- and anterior-directed ACoA aneurysms can easily be clipped using a supraorbital keyhole approach, large superior-directed and high-positioned ACoA aneurysms require a pterional-transsylvian approach or interhemispheric approach.

Besides the location of the aneurysm, its size and shape can also affect the selection of the surgical approach. For example, a large-size and wide-necked aneurysm and the adjacent location of multiple aneurysms can require a larger craniotomy for the application of multiple clips in various directions. For MCA aneurysms, a maximum diameter $<15 \mathrm{~mm}$ and neck diameter $<10 \mathrm{~mm}$ are favorable for a supraorbital keyhole approach $^{5}$.

Other relative contraindications for a supraorbital keyhole approach are as follows : 1) tendency of a patient to form keloids and hypertrophic scars, 2) asymmetric sagging brows, and 3) anticipated emotional stress due to even a small operative wound on the face ${ }^{15}$.

\section{Ruptured aneurysms}

The application of a keyhole approach to ruptured intracranial aneurysms remains controversial due to the surgical difficulties associated brain swelling, whereas unruptured aneurysms are a good indication for a supraorbital keyhole approach.

Achieving adequate brain relaxation is critical for keyhole surgery in cases of brain swelling after a subarachnoid hemorrhage. An intravenous mannitol infusion and drainage of the cerebrospinal fluid using an intraoperative ventriculostomy or lumbar drainage can facilitate aneurysm clipping via a keyhole approach for patients with a ruptured aneurysm. Keyhole surgery is considered an acceptable option especially for patients with a good clinical grade and small subarachnoid hem-

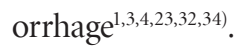

\section{COSMETIC CONCERNS AND RESULTS}

Although a supraorbital keyhole approach minimizes the surgical wound, the small surgical wound still raises cosmetic concerns. Even a small operative scar in the face can be disfiguring. Furthermore, the risk of postoperative palsy of the frontalis muscle is a serious drawback of this approach. Therefore, the following sections present various technical solutions to improve the cosmetic results.

\section{Palsy of the frontalis muscle}

The facial nerve exits the skull base through the stylomastoid foramen and then divides into five major facial branches. 
The course of the uppermost branch, the frontal branch, can be traced as a line starting from a point $0.5 \mathrm{~cm}$ below the tragus and passing $1.5 \mathrm{~cm}$ above the lateral extremity of the eyebrow $^{24)}$. The incidence of permanent palsy of the frontalis muscle after a supraorbital keyhole approach has been reported as $5.5 \%$ by Reisch and Perneczky ${ }^{28}$, whereas no permanent palsy was reported by Park et al. ${ }^{19,222}$.

Temporary palsy of the frontalis muscle is considered related to stretch-induced nerve injuries occurring during retraction of the operative wound when the skin incision does not transect the frontal branch. The exact location of the frontal branch of the facial neve varies individually. If the frontal branch is close to the skin incision, this increases the incidence and duration of palsy of the frontalis muscle.

A study of preoperative percutaneous mapping of the frontal branch using a nerve conduction study of 52 patients who underwent a supraorbital keyhole approach was previously performed by Park et al. ${ }^{19)}$ The results identified four types of distribution of the frontal branch of the facial nerve in the forehead. Although no permanent palsy of the frontalis was observed, the incidence of transient severe palsy of the frontalis muscle was shown to vary according to the proximity of the frontal branch to the supraorbital margin as follows : 1) between 2 and $3 \mathrm{~cm}$ from the supraorbital margin in 51.9\% of the patients showed a $7.4 \%$ incidence of transient severe palsy of the frontalis muscle, 2) bimodal distribution with one branch between 2 and $3 \mathrm{~cm}$ and the other branch between 1 and $1.5 \mathrm{~cm}$ from the supraorbital margin in $26.9 \%$ of the patients showed a $14.3 \%$ incidence, 3$) 1.5 \mathrm{~cm}$ from the supraorbital margin in $9.6 \%$ of the patients showed a $40.0 \%$ incidence, and 4) approximately $1.0 \mathrm{~cm}$ from the supraorbital margin in $11.5 \%$ of the patients showed a $83.3 \%$ incidence.

Accordingly, a skin incision located $\leq 1 \mathrm{~cm}$ from the supraorbital margin can avoid permanent palsy of the frontalis muscle. Transient severe palsy of the frontalis muscle usually lasts 2 to 5 months postoperatively, yet cases of transient frontalis palsy lasting 2 years have also been reported ${ }^{22}$. Thus, preoperative mapping of the frontal branch using a nerve conduction study can estimate the risk of transient severe palsy of the frontalis muscle and affect selection of the best surgical approach. Notwithstanding, preoperative mapping of the frontal branch is rarely performed, as the risk of permanent palsy of the frontalis is extremely low.

Following the skin incision, the underlying muscles are cut using monopolar cautery. However, subcutaneous undermining to facilitate a craniotomy should be performed using a blunt dissector instead of monopolar cautery. Serious consideration should be given to a thermal injury to the frontal branch of the facial nerve.

\section{Cosmetic results}

As regards cosmetic results, a pterional approach can produce an anterior temporal hollow and long operative scar at the front of the head. This long frontal scar can be associated with hair loss and disfigurement, which is especially problematic for patients who are bald, have a high forehead, or have thinning hair. In contrast, a supraorbital keyhole approach does not create an anterior temporal hollow or long operative scar in the scalp, yet can produce frontalis palsy and a disfiguring facial wound. The shorter the skin incision on the face, the better the cosmetic outcome. The shortest skin incision without limiting the maneuverability of the surgical instruments in a supraorbital keyhole approach is $3.5 \mathrm{~cm}$ in length.

Patient age also affects the cosmetic results of a supraorbital keyhole approach. For younger patients aged $<50$ years, the operative wound invariably heals well with an excellent cosmetic appearance. However, for elderly patients aged $>70$ years, the operative scar often leaves a linear depression and slightly sagging brow due to loose skin.

Park et al. ${ }^{21)}$ conducted a patient satisfaction survey on 21 patients who underwent an ipsilateral superciliary keyhole approach and contralateral pterional approach for bilateral intracranial aneurysms. When asked about the cosmetic results for the supraorbital approach vs. the pterional approach, $76.2 \%$ of the patients complained about the cosmetic results for the pterional approach side due to a loss of frontal hair along the operative scar, disfiguring scar, and anterior temporal hollow, whereas only $14.3 \%$ of the patients had minor cosmetic complaints for the supraorbital approach side due to the operative scar. Although the pterional approach did not leave a facial scar, it produced a higher cosmetic complaint score, as the operative scar behind the hairline was visible in many patients due to hair loss along the scar and the patient's thinning hair. 


\section{ADVANTAGES OF SUPRAORBITAL KEYHOLE APPROACH}

When compared with a pterional approach and its modifications, a supraorbital keyhole approach has many advantages ${ }^{15)}$. First, a supraorbital keyhole approach minimizes the iatrogenic traumatization to the cranium. As a craniotomy is very small, the intraoperative blood loss is negligible and a postoperative epidural hematoma is rare. The wound-related pain is also minimized. Second, the damage to the temporalis muscle is minimal in the case of a supraorbital keyhole approach. Only the temporalis covering the frontobasal lateral burrhole is cut using monopolar cautery, thereby avoiding any limited mouth opening or significant anterior temporal hollow. Third, a supraorbital keyhole approach is not associated with a long scar on the scalp and an associated hair loss. Fourth, it facilitates straightforward access to the lesion and the operative duration is very short. A supraorbital mini-craniotomy takes 20 minutes, while intradural access to an aneurysm and clipping take another 30 minutes for small, non-complicated aneurysms. Fifth, a supraorbital keyhole approach allows an early return to work and social life. Even in cases of no postoperative neurological deficits, many pterional approach patients experience significant swelling of the temporalis and operative wound for several weeks, and encounter difficulties in normal social life for a while.

\section{PATIENT SATISFACTION AFTER SUPRAORBIT- AL KEYHOLE APPROACH}

Understanding the technical limitations, applying the appropriate surgical indications, and gaining sufficient surgical experience of a supraorbital keyhole approach allow the surgical goal of aneurysm surgery to be achieved in a minimally invasive manner, which means complete aneurysm clipping without neurological deficits. For small unruptured aneurysms at or around the circle of Willis, the clipping status and postoperative neurological state resulting from a supraorbital keyhole approach are not inferior to those when using a conventional approach ${ }^{3,7,8,22,25)}$.

After achieving the surgical goal, the patient satisfaction level is affected by the invasiveness of the surgical approach. When patients who underwent both an ipsilateral supraorbital keyhole approach and a contralateral pterional approach for bilateral aneurysms were asked to compare their experience, their overall satisfaction level was significantly higher for the supraorbital keyhole approach ${ }^{21}$. As regards their ptrional experience, the complaint scores were higher for the cosmetic results, palpable cranial irregularities, and craniotomy-related pain at or around the bone flap.

\section{CONCLUSION}

Despite the technical concerns due to a small cranial opening, a supraorbital keyhole approach allows small unruptured anterior circulation aneurysms at or around the circle of Willis to be clipped safely in a minimally invasive manner. In addition, the cosmetic results are excellent with a high level of patient satisfaction.

\section{CONFLICTS OF INTEREST}

No potential conflict of interest relevant to this article was reported.

\section{INFORMED CONSENT}

This type of study does not require informed consent.

\section{AUTHOR CONTRIBUTIONS}

\author{
Conceptualization : JP \\ Data curation : JP \\ Formal analysis : JP \\ Funding acquisition : JP \\ Methodology : JP \\ Project administration : JP \\ Visualization : JP \\ Writing - original draft : JP \\ Writing - review \& editing: JP
}




\section{References}

1. Brydon HL, Akil H, Ushewokunze S, Dhir JS, Taha A, Ahmed A : Supraorbital microcraniotomy for acute aneurysmal subarachnoid haemorrhage: results of first 50 cases. Br J Neurosurg 22 : 40-45, 2008

2. Cardali S, Romano A, Angileri FF, Conti A, La Torre D, de Divitiis 0 , et al. : Microsurgical anatomic features of the olfactory nerve: relevance to olfaction preservation in the pterional approach. Neurosurgery 57 (1 Suppl) : 17-21, 2005

3. Chalouhi $N$, Jabbour P, Ibrahim I, Starke RM, Younes P, El Hage G, et al. : Surgical treatment of ruptured anterior circulation aneurysms: comparison of pterional and supraorbital keyhole approaches. Neurosurgery 72 : 437-441, 2013

4. Chen L, Tian X, Zhang J, Huang Y, Chen E, Lan Q : Is eyebrow approach suitable for ruptured anterior circulation aneurysms on early stage: a prospective study at a single institute. Acta Neurochir (Wien) 151 : 781-784, 2009

5. Choi YJ, Son W, Park KS, Park J : Intradural procedural time to assess technical difficulty of superciliary keyhole and pterional approaches for unruptured middle cerebral artery aneurysms. J Korean Neurosurg Soc 59 : 564-569, 2016

6. Goh DH, Kim GJ, Park J : Medpor craniotomy gap wedge designed to fill small bone defects along cranial bone flap. J Korean Neurosurg Soc 46 : 195-198, 2009

7. Lan Q, Gong Z, Kang D, Zhang H, Qian Z, Chen J, et al. : Microsurgical experience with keyhole operations on intracranial aneurysms. Surg Neurol 66 Suppl 1 : S2-S9, 2006

8. Lan Q, Zhang H, Zhu Q, Chen A, Chen Y, Xu L, et al. : Keyhole approach for clipping intracranial aneurysm: comparison of supraorbital and pterional keyhole approach. World Neurosurg 102 : 350-359, 2017

9. Lee YS, Park J : Anterior choroidal artery aneurysm surgery: ischemic complications and clinical outcomes revisited. J Korean Neurosurg Soc 54 : 86-92, 2013

10 Mitchell P, Vindlacheruvu RR, Mahmood K, Ashpole RD, Grivas A, Mendelow $A D$ : Supraorbital eyebrow minicraniotomy for anterior circulation aneurysms. Surg Neurol 63 : 47-51, 2005

11. Mori K, Wada K, Otani N, Tomiyama A, Toyooka T, Takeuchi S, et al. : Keyhole strategy aiming at minimizing hospital stay for surgical clipping of unruptured middle cerebral artery aneurysms. J Neurosurg 130 : 1039-1408, 2019

12. Paladino J, Mrak G, Miklic P, Jednacak H, Mihaljevic D : The keyhole concept in aneurysm surgery--a comparative study: keyhole versus standard craniotomy. Minim Invasive Neurosurg 48 : 251-258, 2005

13. Park HS, Park SK, Han YM : Microsurgical experience with supraorbital keyhole operations on anterior circulation aneurysms. J Korean Neurosurg Soc 46 : 103-108, 2009

14. Park J : Self-drilling anchor screws for dural tenting sutures: technical note. Surg Neurol 72 : 175-176, 2009

15. Park J : Superciliary keyhole approach for unruptured anterior circulation aneurysms: surgical technique, indications, and contraindications. J Korean Neurosurg Soc 56 : 371-374, 2014
16. Park J : Clip-knotting technique for intracranial arterial suturing through deep and narrow surgical corridors-how I do it. Acta Neurochir (Wien) $157:$ 769-771, 2015

17. Park J, Hwang YH, Huh S, Kang DH, Kim Y : Minimally invasive and rapid surgical embolectomy (MIRSE) as rescue treatment following failed endovascular recanalization for acute ischemic stroke. Acta Neurochir (Wien) $156:$ 2041-2049, 2014

18. Park J, Hwang YH, Kim Y : Extended superciliary approach for middle cerebral artery embolectomy after unsuccessful endovascular recanalization therapy: technical note. Neurosurgery 65 : E1191-E1194, 2009

19. Park J, Jung TD, Kang DH, Lee SH : Preoperative percutaneous mapping of the frontal branch of the facial nerve to assess the risk of frontalis muscle palsy after a supraorbital keyhole approach. J Neurosurg 118 : 1114-1119, 2013

20. Park J, Kang DH, Chun BY : Superciliary keyhole surgery for unruptured posterior communicating artery aneurysms with oculomotor nerve palsy: maximizing symptomatic resolution and minimizing surgical invasiveness. J Neurosurg 115 : 700-706, 2011

21. Park J, Son W, Kwak Y, Ohk B : Pterional versus superciliary keyhole approach: direct comparison of approach-related complaints and satisfaction in the same patient. J Neurosurg $130: 220-226,2018$

22. Park J, Woo H, Kang DH, Sung JK, Kim Y : Superciliary keyhole approach for small unruptured aneurysms in anterior cerebral circulation. Neurosurgery 68 (2 Suppl Operative) : 300-309, 2011

23. Park JS, Kim H, Baik MW, Park IS : Risk factor analysis for poor outcomes in supraorbital keyhole aneurysm clipping for ruptured anterior circulation aneurysms. World Neurosurg 111 : e386-e394, 2018

24. Pitanguy I, Ramos AS : The frontal branch of the facial nerve: the importance of its variations in face lifting. Plast Reconstr Surg 38 : 352356, 1966

25. Raaymakers TW, Rinkel GJ, Limburg M, Algra A : Mortality and morbidity of surgery for unruptured intracranial aneurysms: a meta-analysis.

Stroke 29 : 1531-1538, 1998

26. Ramos-Zúñiga $R$, Velázquez $H$, Barajas MA, López $R$, Sánchez E, Trejo S : Trans-supraorbital approach to supratentorial aneurysms. Neurosurgery 51 : 125-130, 2002

27. Reisch R, Marcus HJ, Kockro RA, Ulrich NH : The supraorbital keyhole approach: how I do it. Acta Neurochir (Wien) 157 : 979-983, 2015

28. Reisch R, Perneczky A : Ten-year experience with the supraorbital subfrontal approach through an eyebrow skin incision. Neurosurgery 57 (4 Suppl) : 242-255, 2005

29. Rychen J, Croci D, Roethlisberger M, Nossek E, Potts M, Radovanovic I, et al. : Minimally invasive alternative approaches to pterional craniotomy: a systematic review of the literature. World Neurosurg 113 : 163179, 2018

30. Shin D, Park J : Unruptured supraclinoid internal carotid artery aneurysm surgery: superciliary keyhole approach versus pterional approach. J Korean Neurosurg Soc 52 : 306-311, 2012

31. Tomii $M$ : Strength testing of the human olfactory nerve at the frontal skull base. Neurosurg Rev 35 : 555-560, 2012

32. Tra H, Huynh T, Nguyen B : Minipterional and supraorbital keyhole crani- 
otomies for ruptured anterior circulation aneurysms: experience at single center. World Neurosurg 109 : 36-39, 2018

33. van Lindert $E$, Perneczky A, Fries $G$, Pierangeli $E$ : The supraorbital keyhole approach to supratentorial aneurysms: concept and technique. Surg Neurol 49 : 481-489, 1998

34. Yu LB, Huang Z, Ren ZG, Shao JS, Zhang Y, Wang R, et al. : Supraorbital keyhole versus pterional craniotomies for ruptured anterior communicating artery aneurysms: a propensity score-matched analysis. Neurosurg Rev, 2018 [Epub ahead of print]

35. Zumofen DW, Rychen J, Roethlisberger M, Taub E, Kalbermatten $D$, Nossek $E$, et al. : A review of the literature on the transciliary supraorbital keyhole approach. World Neurosurg 98 : 614-624, 2017 